\title{
Impact of treatment of sleep apnoea on left ventricular function in congestive heart failure
}

\author{
M T Naughton
}

Congestive heart failure $(\mathrm{CHF})$ is a disorder associated with an increasing prevalence and a mortality greater than many malignancies. ${ }^{1}$ Its prevalence has doubled in the last 20 years $^{2}$ mainly as a result of improved myocardial infarction survival. ${ }^{3}$ In terms of mortality, over $50 \%$ of patients diagnosed with $\mathrm{CHF}$ today will be dead in five years. ${ }^{1}$ Unfortunately, despite advances in medical treatments-in particular angiotensin converting enzyme inhibitorssurvival has improved only marginally. ${ }^{4}$ Whether $\beta$ adrenergic blockers offer a true survival benefit is currently debated. ${ }^{56}$ Clearly, other therapeutic modalities need to be developed.

This brief review discusses the role of sleep apnoea and its reversal with continuous positive airway pressure (CPAP) in patients with CHF. Discussion will focus initially upon the rationale for CPAP in acute unstable and chronic stable CHF. Thereafter, the influence of long term treatments of sleep apnoea (CPAP and other treatments) on cardiac function in patients with chronic $\mathrm{CHF}$ will be discussed.

As early as 1936 positive airway pressure was used to treat acute cardiogenic pulmonary oedema. ${ }^{7}$ Since then, many clinicians have reported improvements in cardiopulmonary physiology such as arterial blood gas tensions and work of breathing in patients with acute cardiogenic pulmonary oedema who were mechanically ventilated with positive end expiratory pressure (PEEP). ${ }^{8}$ Similar reports were observed in patients with cardiogenic pulmonary oedema breathing spontaneously with $\mathrm{CPAP}^{9-11}$ compared with standard medical treatment alone. Moreover, CPAP delivered via an oronasal or nasal mask has been shown to reduce the need for tracheal intubation and invasive ventilation, to reduce the length of stay in intensive care, and has a tendency for increased in-hospital survival in patients with acute decompensated CHF compared with medical treatment alone. ${ }^{10}$ In patients with stable CHF short term CPAP may also have a beneficial effect. In patients with stable $\mathrm{CHF}$ due to idiopathic dilated cardiomyopathy with a raised pulmonary capillary wedge pressure $(>12 \mathrm{~mm} \mathrm{Hg})$, Bradley and colleagues $^{12}$ reported a $22 \%$ improvement in stroke volume index with $5 \mathrm{~cm} \mathrm{H}_{2} \mathrm{O}$ CPAP given for $10 \mathrm{~min}-$ utes compared with no CPAP. Patients with $\mathrm{CHF}$ in whom pulmonary artery wedge pressure was $<12 \mathrm{~mm} \mathrm{Hg}$ experienced no significant change in stroke volume index. Later, the same group showed a similar "dose dependent effect" of increasing levels of CPAP $(0,5$ and $10 \mathrm{~cm} \mathrm{H}_{2} \mathrm{O}$ ) on stroke volume index in a similar group of patients with raised pulmonary capillary wedge pressure. ${ }^{13}$ Recently, Liston and co-workers observed a $20 \%$ reduction in stroke volume index in a group of seven patients with a mean pulmonary artery wedge pressure of $21 \mathrm{~mm} \mathrm{Hg}$ given $5 \mathrm{~cm} \mathrm{H}_{2} \mathrm{O}$ CPAP over a three hour period. ${ }^{14}$ Baratz et al observed an increased stroke volume index of $16 \%$ in seven of 13 patients with decompensated $\mathrm{CHF}$ and pulmonary artery capillary wedge pressure of $>20 \mathrm{~mm} \mathrm{Hg}$ given $5-15 \mathrm{~cm} \mathrm{H}_{2} \mathrm{O}$ CPAP for 20-60 minutes. ${ }^{11}$ No significant change was seen in the remaining patients. Patient selection, study design, or technical factors may be responsible for variation in results. Further studies are required to confirm these findings and to determine whether the effects are applicable during sleep.

The mechanisms responsible for the beneficial short term effects of CPAP upon cardiac function in awake patients with $\mathrm{CHF}$ are likely to be numerous. That stroke volume of the failing heart increases with reductions in afterload is the basis for the use of systemic arterial vasodilators in treating CHF. Positive airway pressure, either as CPAP or PEEP, can provide a reduction in afterload by virtue of increasing intrathoracic pressure. In a controlled study CPAP caused an increase in intrathoracic pressure (measured by oesophageal balloon) without change in systemic arterial systolic pressure, suggesting a fall in the left ventricular (LV) transmural pressure gradient in a group of awake patients with stable $\mathrm{CHF}^{15}$ Moreover, the product of heart rate and LV transmural pressure gradient was shown to fall in such patients with CPAP treatment, suggesting a fall in cardiac work. ${ }^{15}$ Furthermore, canine studies suggest that $\mathrm{LV}$ end diastolic volume is reduced with up to $20 \mathrm{~cm} \mathrm{H}_{2} \mathrm{O}$ CPAP. ${ }^{16}$ Both LV transmural pressure gradient and LV end diastolic volume are factors which contribute to LV afterload by virtue of the Laplace relationship. Furthermore, CPAP has been shown to increase end expiratory lung volume, to assist inspiratory respiratory muscles, ${ }^{17}$ and to impede venous return. CPAP therefore has a number of potential actions in improving left ventricular function and pulmonary oedema in the awake patient with $\mathrm{CHF}$ that are independent of the presence of apnoea.

Sleep apnoea is commonly found in patients with CHF. Based upon full overnight polysomnography in 42 patients with stable CHF (left ventricular ejection fraction (LVEF) $\leqslant 45 \%$ ), $45 \%$ of patients had more than 20 apnoeas or hypopnoeas per hour of sleep of both obstructive and central types. ${ }^{18}$ Obstructive sleep apnoea (OSA), in which upper airway instability is pathognomonic, is characterised by hypoxaemia and hypercapnia, large negative or subatmospheric intrathoracic pressures, widely oscillating systemic arterial pressures, 
and frequent arousals which fragment sleep. Scharf and coworkers ${ }^{19}$ and Buda and colleagues $^{20}$ both reported that negative intrathoracic pressure of $30 \mathrm{~cm} \mathrm{H}_{2} \mathrm{O}$ for 7-15 seconds impaired LVEF and at a negative pressure of $60 \mathrm{~cm} \mathrm{H}_{2} \mathrm{O}$ there were also increased LV end systolic and end diastolic volumes. These findings suggest that negative intrathoracic pressures have a detrimental effect upon LVEF in patients with impaired cardiac contractility, most probably due to increases in LV afterload-that is, LV transmural pressure gradient and LV end diastolic volume.

Reversal of OSA has been shown to augment LVEF. In 29 patients reversal of OSA with nocturnal CPAP over a 12 month period was shown to improve awake LVEF from $59 \%$ to $63 \% .{ }^{21}$ In this later study by Krieger and colleagues $^{21}$ there was no clinical evidence of $\mathrm{CHF}$ in the patient population, although at baseline eight patients had an LVEF of $<55 \%$ and two patients had an LVEF of $<45 \%$, suggesting that some CHF was probably present at baseline although was not recognised as such. In a more recent study by Malone and coworkers eight men with idiopathic dilated cardiomyopathy and coexistent OSA underwent treatment with nocturnal CPAP for four weeks which resulted in significant improvements in awake LVEF (37\% to $49 \%$ ) and NYHA symptom classification. ${ }^{22}$ Following withdrawal of CPAP in a subset of the same population there was a significant reduction in LVEF (from 53\% to $45 \%$ ) and symptoms. ${ }^{22}$ It is therefore likely that obstructive sleep apnoea contributes to the development of CHF. More importantly, treatment of OSA with CPAP results in improved LVEF and symptoms.

Central sleep apnoea is characterised by hyperventilation, hypocapnia, and circulatory delay which culminate in respiratory control instability. ${ }^{23}$ Clinically, central sleep apnoea manifests as orthopnoea, paroxysmal nocturnal dyspnoea, unrefreshing nocturnal sleep, and excessive daytime sleepiness. Snoring is frequently absent. Polysomnography reveals typical central apnoeas with a crescendo/decrescendo ventilatory pattern described by Harrison et al as Cheyne-Stokes respiration ${ }^{24}$ and others as periodic breathing. Occasionally, one or two obstructive efforts may occur at the end of the apnoea. ${ }^{25}$ Two independent reports suggest that patients with central sleep apnoea have a worse prognosis than patients with $\mathrm{CHF}$ without central sleep apnoea. ${ }^{26}$ Of 15 patients with severe $\mathrm{CHF}$, Findley and colleagues ${ }^{26}$ reported six month mortality to be $100 \%$ in the six patients with central sleep apnoea compared with $33 \%$ in the patients without central sleep apnoea. More recently, in a study of 16 patients with severe $\mathrm{CHF}$, Hanly et al reported three year mortality to be $56 \%$ in patients with central sleep apnoea compared with $11 \%$ in those without central sleep apnoea, all of whom had similar degrees of CHF based upon $\mathrm{LVEF}^{27}$ It is therefore likely that central sleep apnoea is an adverse risk factor for mortality in CHF. Moreover, a vicious cycle between $\mathrm{CHF}$ and central sleep apnoea may develop, central sleep apnoea beginning in a possibly predisposed individual who is exposed to poor cardiac function and thereby circulatory delay and hyperventilation. ${ }^{23}$ However, through mechanisms of central sleep apnoea induced sleep fragmentation and hypoxaemia, increases in sympathoneural activity may occur and thereby contribute to worsening cardiac function. ${ }^{28}$

Treatments aimed at controlling central sleep apnoea related to $\mathrm{CHF}$ can be divided into those which stimulate ventilation and override the periodic breathing pattern akin to a cardiac pacemaker, and those directed towards improving underlying cardiac function. Treatments known to stimulate ventilation, which include inhaled carbon dioxide ${ }^{29}$ and theophylline, ${ }^{30}$ have been shown to reduce the severity of central sleep apnoea over a short period (less than a week). Javaheri et al reported no significant changes in LVEF or symptoms in a double blind study of theophylline for five days in 15 men with compensated $\mathrm{CHF}$ and sleep disordered breathing. ${ }^{30}$ Other groups have sought to determine the effects of benzodiazepines, which are thought to suppress arousability and ventilation. Although arousal frequency fell, there were no significant effects upon the degree of central sleep apnoea nor in the measures of oxygenation. ${ }^{31}{ }^{32}$

Alternatively, inhaled oxygen, which would also reduce ventilatory drive and possibly improve cardiac function through removal of hypoxaemia, has been used in the management of central sleep apnoea in patients with CHF. Supplemental overnight oxygen has been shown to reduce severity of central sleep apnoea when given for a single night ${ }^{33}{ }^{34}$ and over seven nights. ${ }^{35}$ In the first reported study of the effects of oxygen upon central sleep apnoea in nine patients with CHF Hanly and colleagues observed a statistically significant fall in apnoea/hypopnoea index (AHI) from 30 to 19 events per hour with a single night of intranasal oxygen at a rate of $2-31 / \mathrm{min}$ in a randomised single blind study. ${ }^{33}$ Walsh and coworkers $^{34}$ reported a similar fall in the severity of central sleep apnoea (AHI fell from 32 to 23 events per hour, $\mathrm{p}<0.05$ ) in a nonrandomised study of intranasal oxygen given at a rate of $2 \mathrm{l} / \mathrm{min}$ for one night in seven patients. Recently, Andreas et al reported a greater fall in central sleep apnoea (AHI fell from 26 to 10 events per hour) in 22 patients given intranasal oxygen $41 / \mathrm{min}$ for seven days in a randomised double blind crossover study. ${ }^{35}$ Although there were improvements in peak oxygen uptake on incremental cycle ergometer exercise testing in this study (from 835 to $960 \mathrm{ml} / \mathrm{min}, \mathrm{p} \mathrm{<0.05),}$ neither the duration of exercise, peak heart rate, nor quality of life were improved..$^{35}$ There have been no studies in which objective measures of cardiac function such as LVEF have been measured under controlled situations. It is therefore likely that supplemental intranasal oxygen does reduce the severity of central sleep apnoea in patients with $\mathrm{CHF}$, at least over a brief period; however, whether there is a beneficial effect upon cardiac function remains to be seen. 
Agents that improve underlying cardiac dysfunction have had greater success in the management of central sleep apnoea. Captopril reduced the severity of central sleep apnoea by $50 \%$ over a four week period in an open observational study of eight patients (AHI fell from 35 to 20 events per hour)..$^{34}$

In a randomised controlled study of CPAP in patients with stable CHF with central sleep apnoea on optimal medical treatment, sleep studies were performed at one month and LVEF and symptom scores at three months. ${ }^{36}$ Treatment with CPAP was shown to reduce the severity of central sleep apnoea significantly from 43 to 15 events per hour compared with the non-CPAP group in whom the AHI fell from 33 to 27 events per hour. ${ }^{36}$ Moreover, at three months there were significant improvements in LVEF and quality of life symptom scores associated with reductions in hospitalisation rates. ${ }^{36}$ In addition, overnight ventilation and sympathoneural activity were reduced at one month. ${ }^{28}{ }^{37}$ Fourteen percent of the patients with $\mathrm{CHF}$ and central sleep apnoea randomised to receive CPAP dropped out of the study because of mask discomfort and there were no deaths or serious side effects seen with CPAP. ${ }^{36}$

As changes in LVEF at three months have been shown to predict long term survival, ${ }^{38}$ and increased sympathoneural activity is an adverse risk factor for mortality in $\mathrm{CHF},{ }^{1}$ it is likely that treatment with CPAP in this subgroup of patients with $\mathrm{CHF}$ would translate into improved survival. It is of paramount importance to emphasise that CPAP in these subjects was instituted under medical supervision over $2-3$ nights, beginning at a pressure of $5 \mathrm{~cm} \mathrm{H}_{2} \mathrm{O}$ and gradually increasing over a four week period to a level of at least $10 \mathrm{~cm} \mathrm{H}_{2} \mathrm{O}$. Repeat polysomnography was performed at four weeks. This contrasts with the titration of CPAP in obstructive sleep apnoea in which pressure is titrated acutely during polysomnography to prevent upper airway collapse. Other studies of CPAP in central sleep apnoea have not shown similar positive results, ${ }^{31} 3940$ possibly because of shorter treatment regimes (less than two weeks), brief duration of titration, and lower levels of CPAP (frequently less than 10 $\mathrm{cm} \mathrm{H}_{2} \mathrm{O}$ ) using a heterogeneous $\mathrm{CHF}$ patient population. The studies from Toronto have been limited to patients with either idiopathic dilated or ischaemic cardiomyopathy.

In summary, CPAP has a number of actions which might augment the failing heartnamely, reducing LV transmural pressure gradient $^{15}$ and $\mathrm{LV}$ end diastolic volume, ${ }^{16}$ assisting inspiratory muscles, increasing end expiratory lung volume, ${ }^{17}$ and impeding venous return. In addition to these specific cardiopulmonary effects, reversal of coexistent sleep apnoea may have additional beneficial effects. Reversal of OSA with nocturnal CPAP has been shown to improve awake objective and subjective markers of $\mathrm{CHF}^{22}$ Reversal of central sleep apnoea and subsequent improvement in cardiac function has only been demonstrated with $\mathrm{CPAP}^{36}$ although some evidence exists to suggest that angiotensin converting enzyme inhibitors ${ }^{34}$ and oxygen ${ }^{35}$ may have a beneficial effect as well. Further research into the management of sleep apnoea and heart failure is crucial if inroads are to be made into the management of heart failure which carries such a dreadful prognosis.

1 Ho KKL, Anderson KM, Kannel WB, et al. Survival after the onset of congestive heart failure in Framingham Heart the onset of congestive heart failure in Fram

2 Smith WM. Epidemiology of congestive heart failure. Am f Cardiol 1985;55:3-8A

3 McGovern PG, Pankow JS, Shahar E, et al. Recent trends in acute coronary heart disease. N Engl f Med 1996;334:88490

4 Cohn JN, Johnson G, Ziesche S, et al. A comparison of enalapril with hydrallazine-isosorbide dinitrate in the treatment of chronic congestive heart failure. N Engl F Med 1991;325: 303-10.

5 Packer M, Bristow MR, Cohn J, et al. The effect of carvedilol on morbidity and mortality in patients with chronic heart failure. N Engl f Med 1996;334:1349-55.

6 Pfeffer MA, Stevenson LW. $\beta$-adrenergic blockers and survival in heart failure. N Engl F Med 1996;334:1396-7.

7 Poulton EP. Left-sided heart failure with pulmonary oedema. Its treatment with the "pulmonary plus pressure machine". Lancet 1936:981-3.

8 Grace MP, Greenbaum DM. Cardiac performance in response to PEEP in patients with cardiac dysfunction. Crit response to PEEP in patien
Care Med 1982;10:358-60.

9 Rasanen J, Heikkila J, Downs J, et al. Continuous positive airway pressure by face mask in acute cardiogenic pulmony edema. Am f Cardiol 1985;55:296-300.

10 Bersten AD, Holt AW, Vedig AE, et al. Treatment of severe cardiogenic pulmonary edema with continuous positive airway pressure delivered by a face mask. $N$ Engl f Med 1991;325:1825-30.

11 Baratz DM, Westbrook PR, Shah PK, et al. Effect of nasal continuous positive airway pressure on cardiac output and oxygen delivery in patients with congestive heart failure. Chest 1992;102:1397-401.

12 Bradley TD, Holloway RM, McLaughlin PR, et al. Cardiac output response to continuous positive airway pressure in congestive heart failure. Am Rev Respir Dis 1992;145:37782 .

13 De Hoyos A, Liu PP, Benard DC, et al. Haemodynamic effects of continuous positive airway pressure in humans
with normal and impaired left ventricular function. Clin Sci with normal and

14 Liston R, Deegean PC, McCreery C, et al. Haemodynamic effects of nasal continuous positive airway pressure in severe congestive heart failure. Eur Respir f 1995;8:430-5.

15 Naughton MT, Rahman MA, Hara K, et al. Cardiothoracic effects of continuous positive airway pressure in patients with heart failure. Circulation 1995;91:1725-31.

16 Fewell JE, Abendschein DR, Carlson CJ, et al. Continuous positive pressure ventilation decreases right and left ventricular end-diastolic volumes in the dog. Circ Res 1980; 46:125-32.

17 Naughton MT, Bookman I, Floras JS, et al. Effect of CPAP on respiratory mechanics in heart failure. Am F Respir Crit Care Med 1995;151:A706.

18 Javaheri S, Parker TJ, Wexler L, et al. Occult sleepdisordered breathing in stable congestive heart failure. Ann Intern Med 1995;122:487-92.

19 Scharf SM, Bianco JA, Tow DE, et al. The effects of large negative intrathoracic pressure on left ventricular function in patients with coronary artery disease. Circulation 1981;63:871-5.

20 Buda AJ, Pinsky MR, Ingels NB, et al. Effect of intrathoracic pressure on left ventricular performance. $N$ Engl $\mathcal{F}$ Med 1979;301:453-9.

21 Krieger J, Grucker D, Sforza E, et al. Left ventricular ejection fraction in obstructive sleep apnea. Effect of long term treatment with nasal continuous positive airway pressure. Chest 1991;100:917-21.

22 Malone S, Liu PP, Holloway R, et al. Obstructive sleep apnoea in patients with idiopathic dilated cardiomyoathy: effects of continuous positive airway pressure. Lancet 1991; 338: $1480-4$.

23 Naughton MT, Benard D, Tam A, et al. Role of hyperventilation in the pathogenesis of central sleep apneas in patients with co $330-8$.

24 Harrison TR, King CE, Calhoun JA, et al. Congestive heart failure. Cheyne-Stokes respiration as the cause of paroxysmal nocturnal dyspnea at the onset of sleep. Arch Intern Med 1934;53:891-910

25 Alex CG, Onal E, Lopata M. Upper airway occlusion during sleep in patients with Cheyne-Stokes respiration. Am Rev Respir Dis 1986;133:42-5.

26 Findley LJ, Zwillich CW, Ancoli-Israel S, et al. CheyneStokes breathing during sleep in patients with left ventricular heart failure. South Med $\mathcal{F}$ 1985;78:11-15.

27 Hanly PJ, Zuberi-Khokhar NS. Increased mortality associated with Cheyne-Stokes respiration in patients with congestive heart failure. Am f Respir Crit Care Med 1996;153:272-6.

28 Naughton MT, Benard DC, Liu PP, et al. Effects of nasal CPAP on sympathetic activity in patients with heart failure and central sleep apnea. Am $\mathcal{f}$ Respir Crit Care Med 1995;152:473-9. 
29 Steens RD, Millar TW, Xiaoling S, et al. Effect of inhaled $3 \% \mathrm{CO}_{2}$ on Cheyne-Stokes respiration in congestive heart $3 \% \mathrm{CO}_{2}$ on Cheyne-Stokes
failure. Sleep 1994;17:61-8.

30 Javaheri S, Parker TJ, Wexler L, et al. Effect of theophylline on sleep disordered breathing in heart failure. $N$ Engl f Med 1996;335:562-7.

31 Guilleminault C, Clerk A, Labanowski M, et al. Cardiac failure and benzodiazepines. Sleep 1993;16:524-8

32 Biberdorf DJ, Steens R, Millar TW, et al. Benzodiazepines in congestive heart failure: effects of temazepam on arousability and Cheyne-Stokes respiration. Sleep 1993;16:529-38.

33 Hanly PJ, Millar TW, Steljes DG, et al. The effect of oxygen on respiration and sleep in patients with congestive heart failure. Ann Intern Med 1989;111:777-82.

34 Walsh JT, Andrews R, Starling R, et al. Effects of captopril and oxygen on sleep apnoea in patients with mild to moderate congestive heart failure. Br Heart $\mathcal{F}$ 1995; 73:237-41.

35 Andreas S, Clemens C, Sandholzer H, et al. Improvement of exercise capacity with treatment of Cheyne-Stokes respira-
tion in patients with congestive heart failure. $7 \mathrm{Am}$ Coll
Cardiol 1996:27:1486-90.

36 Naughton MT, Liu PP, Benard DC, et al.Treatment of congestive heart failure and Cheyne-Stokes respiration during leep by continuous positive airway pressure. Am f Respir

37 Naughton MT, Benard DC, Rutherford R, et al. Effect of continuous positive airway pressure on central sleep apnea and nocturnal $\mathrm{PCO}_{2}$ in heart failure. Am $\mathcal{F}$ Respir Crit Care Med 1994;150:1598-604.

38 Cintron G, Johnson G, Francis G, et al. Prognostic significance of serial changes in left ventricular ejection fraction in patients with congestive heart failure. Circulation 1993;87:VI-17-VI-23.

39 Buckle P, Millar T, Kryger M. The effect of short term nasal CPAP on Cheyne-Stokes respiration in congestive heart failure. Chest 1992;102:31-5.

40 Davies RJO, Harrington KJ, Ormerod OJM, et al. Nasal continuous positive airway pressure in chronic heart failure with sleep disordered breathing. Am Rev Respir Dis 1993;147:630-4. 